\title{
Ultrasound-Assisted Saponification Coupled with Gas Chromatography-Flame Ionization Detection for the Determination of Phytosterols from Passion Fruit Seed Oil
}

\author{
Eliza M. Rotta, Michele C. da Silva, Liane Maldaner and Jesuí V. Visentainer* \\ Departamento de Química, Universidade Estadual de Maringá (UEM), \\ Av. Colombo, 5790, 87020-900 Maringá-PR, Brazil
}

\begin{abstract}
An ultrasound-assisted saponification (UAS) method for the determination of phytosterols (campesterol, $\beta$-sitosterol and stigmasterol) in passion fruit seed oil, followed by gas chromatography with flame ionization detection, was developed and validated. Under the optimum conditions, good linearity with correlation coefficients higher than 0.99 was obtained for all analytes. The recoveries for the proposed approach were between 103 and 107\%, the limits of quantification were between 70 and $180 \mu \mathrm{g} \mathrm{kg}^{-1}$ and the precision values expressed in terms of relative standard deviations (RSD) were lower than 19\%. The developed method was successfully applied to the analysis of passion fruit seed oil samples from different species, including yellow passion fruit, sweet granadilla and sweet passion fruit. In all species of analyzed passion fruit seed oils, $\beta$-sitosterol was found with the highest abundance, ranging from $0.90 \pm 0.02$ to $1.60 \pm 0.01 \mathrm{mg} \mathrm{g}^{-1}$ of oil, followed by stigmasterol $\left(0.70 \pm 0.01\right.$ to $1.40 \pm 0.12 \mathrm{mg} \mathrm{g}^{-1}$ of oil $)$ and campesterol $(0.10 \pm 0.01$ to $0.30 \pm 0.06 \mathrm{mg} \mathrm{g}^{-1}$ of oil). Furthermore, the developed method proved to be a time-saving and efficient analytical procedure for the determination of phytosterols in oil samples.
\end{abstract}

Keywords: Passiflora species, campesterol, $\beta$-sitosterol, stigmasterol

\section{Introduction}

Passiflora species are cultivated throughout the world in tropical areas. ${ }^{1-3}$ Passiflora edulis f. flavicarpa (yellow passion fruit), Passiflora alata (sweet passion fruit), Passiflora ligularis (sweet granadilla) and Passiflora edulis Sims (purple passion fruit) are species widely cultivated for their edible fruits. ${ }^{4-6}$ Yellow passion fruit is the species most known and appreciated due to its organoleptic properties, such as an intense flavor and slight acidity. The pulp is destined for in natura consumption, but is predominantly used in juice production. ${ }^{2,4}$ Furthermore, the pulp is known to be rich in bioactive compounds, such as carotenoids, phenolic compounds and vitamins A, C and D. ${ }^{2,7}$

The large-scale production of passion fruit juice generates tons of by-products (peel and seeds) that are important raw materials in the food and cosmetic industries. ${ }^{8}$ Recently, several studies have described that passion fruit peel is a source of fiber, predominantly pectin, which provides it with a range of potential applications as a stabilizer, emulsifier and as a thickening and gelling

*e-mail: jesuiv@gmail.com agent for the preparation of food products, e.g., functional beverages, mayonnaise and ice cream toppings. ${ }^{8-12}$ In addition, it has been reported that passion fruit peel presents antioxidant activity and phenolic compounds. ${ }^{5,13,14}$ Alternatively, passion fruit seeds are described as a rich source of lipids, proteins, minerals and fibers. ${ }^{14-16}$ Several studies have reported that passion fruit seeds contain about $30 \%$ oil, with linoleic, oleic and palmitic acids as the main fatty acids. ${ }^{14,15,17}$ Furthermore, as well as the peel, passion fruit seed oil has been described as a potential source of bioactive compounds, such as phenolic compounds, tocopherols and phytosterols..$^{15,18,19}$

In recent years, passion fruit seeds have been attracting attention in the production of oil, mainly due to the presence of bioactive compounds. ${ }^{16}$ Phytosterols are a group of plant sterols with over 100 compounds that show similar structures and biological functions to cholesterol. ${ }^{20-22} \mathrm{~A}$ number of studies have reported the benefits of a diet rich in phytosterols, especially the ability to reduce the levels of low-density lipoprotein cholesterol in blood and the protective effects against cardiovascular diseases. ${ }^{20-22}$ The most abundant phytosterols found in vegetable oils, seeds, nuts and oil derived products are campesterol, $\beta$-sitosterol and stigmasterol..$^{20,21,23}$ 
Thus, the sample preparation step for the determination of phytosterol compounds generally includes a lipid extraction step, preceded by alkaline hydrolysis known as saponification..$^{24,25}$ Several different methods for lipid extraction and saponification have been described in the literature. Lipid extraction has been extensively performed by the methods described by Folch et al. ${ }^{26}$ and Bligh and Dyer, ${ }^{27}$ and also by Soxhlet extraction. ${ }^{28,29}$ Alternatively, methods that use less toxic reagents, e.g., hexane and ethanol, and extraction techniques, such as ultrasoundassisted extraction (UAE), have been employed to obtain lipid extracts. ${ }^{30,31}$ The saponification step has been carried out based on the use of an ethanolic $\mathrm{KOH}$ solution under controlled conditions of time and temperature. In the related literature, several variations of the saponification step, such as different $\mathrm{KOH}$ concentrations, temperatures and incubation times can be found. ${ }^{24,25,32}$ Moreover, Xiao-Hua et al. ${ }^{25}$ developed a simultaneous method for extraction and saponification employing microwaveassisted extraction for the determination of phytosterols from edible marine algae. However, to the best of our knowledge, the use of ultrasonic radiation during the saponification step has not yet been studied.

The use of UAE for the extraction of lipids and bioactive compounds from plant materials has been widely studied due to the increase in extraction efficiencies and the reduction in time and solvent consumption compared with traditional solvent extractions. ${ }^{30,33,34}$ Extraction efficiency enhancement by ultrasound has been attributed to the formation of microcavities that promote the rupture of cell walls, leading to an increase in mass transfer between the solid and liquid phases. ${ }^{33,34}$ Therefore, the application of ultrasonic radiation in the saponification step can be an alternative to improve the conventional saponification methods, i.e., increasing the extraction efficiency and decreasing the saponification time.

In the present study, we have investigated the potential use of ultrasonic-assisted saponification (UAS) and developed and validated a method for the determination of campesterol, $\beta$-sitosterol and stigmasterol in passion fruit seed oil by gas chromatography-flame ionization detection (GC-FID).

\section{Experimental}

The standards of campesterol, $\beta$-sitosterol and stigmasterol were purchased from Sigma-Aldrich (São Paulo, Brazil), with 65, 95 and 70\% purity, respectively. $\mathrm{KOH}$ and $\mathrm{Na}_{2} \mathrm{SO}_{4}$ were supplied from PANREAC (Barcelona, Spain). Hexane, $n$-heptane, chloroform, methanol and ethanol were acquired from Anidrol (São Paulo, Brazil).

\section{Sampling}

The passion fruits (P. edulis f. flavicarpa, P. alata and $P$. ligularis) were purchased from a local market in Maringá-PR, Brazil. The passion fruit seeds were separated manually from the fruit and stored at $-18^{\circ} \mathrm{C}$ until analysis. Before the lipid extraction step, the seeds were ground until the particle size reached $1.40 \mathrm{~mm}$ (mesh No. 12).

\section{Lipid extraction methods}

The extraction of the lipids of the P. edulis f. flavicarpa seeds was carried out using three different methods, namely, Bligh and Dyer, hexane/ethanol/water and ultrasoundassisted extraction (UAE). ${ }^{27,30,31}$

\section{Bligh and Dyer}

Initially, the passion fruit seeds ( $3 \mathrm{~g}$ ) were transferred to a beaker with a $250 \mathrm{~mL}$ capacity containing $12.0 \mathrm{~mL}$ of distilled water. Then, $45.0 \mathrm{~mL}$ of a solution of chloroform/ methanol $(1: 2 \mathrm{v} / \mathrm{v})$ was added under vigorous stirring for $5 \mathrm{~min}$. After, $15.0 \mathrm{~mL}$ of chloroform was added to the mixture, which was stirred for $2 \mathrm{~min}$, followed by the addition of $15.0 \mathrm{~mL}$ of distilled water and stirring for an additional $5 \mathrm{~min}$. The solution was vacuum filtered on a Büchner funnel with quantitative filter paper and the resulting solution was transferred to a separating funnel. After phase separation (6 h), the lower phase, containing the chloroform and lipids, was transferred to a flask, and the solvent was evaporated in a rotator evaporator (Fisatom, Brazil) kept at approximately $35^{\circ} \mathrm{C}$. The oil was collected in an Eppendorf tube and stored at $-18{ }^{\circ} \mathrm{C}$ for further analysis.

\section{Hexane/ethanol/water}

Initially, the passion fruit seeds $(5 \mathrm{~g})$ were transferred to a beaker with $250 \mathrm{~mL}$ capacity, to which $50.0 \mathrm{~mL}$ of ethanol and $25.0 \mathrm{~mL}$ of hexane were added under vigorous stirring for $5 \mathrm{~min}$. Then, hexane $(25.0 \mathrm{~mL})$ was added and stirred for an additional $2 \mathrm{~min}$. After, $25.0 \mathrm{~mL}$ of distilled water was added and the mixture was stirred for $5 \mathrm{~min}$. The solution obtained was vacuum filtered on a Büchner funnel with quantitative filter paper and the resulting solution was transferred to a separation funnel. Subsequently, after phase separation $(6 \mathrm{~h})$, the lower phase containing the organic solvent and the lipids was collected and the solvent was evaporated in a rotator evaporator (Fisatom, Brazil) at $35^{\circ} \mathrm{C}$. The oil was collected in an Eppendorf tube and stored at $-18{ }^{\circ} \mathrm{C}$ for further analysis. 
Ultrasound-assisted extraction (UAE)

Initially, the passion fruit seeds $(1 \mathrm{~g})$ were transferred to a Falcon tube with a $50.0 \mathrm{~mL}$ capacity, and $25.0 \mathrm{~mL}$ of hexane was added. Then, the mixture was immersed into an ultrasonic bath (Eco-Sonics Q 5.9/25 A, Unique, São Paulo, Brazil), with $165 \mathrm{~W}$ of potency and a frequency of $25 \mathrm{kHz}$ at $60^{\circ} \mathrm{C}$ for $20 \mathrm{~min}$. After extraction, the extract was centrifuged in a Harrier 18/80 Sanyo centrifuge for $10 \mathrm{~min}$ at $6535 \times \mathrm{g}$, and the supernatant was collected. The solvent was evaporated in a rotator evaporator (Fisatom, Brazil) at $35^{\circ} \mathrm{C}$. The oil was collected in an Eppendorf tube and stored at $-18^{\circ} \mathrm{C}$ for further analysis.

\section{Saponification}

\section{Conventional saponification}

Saponification was performed according to Costa et al. ${ }^{35}$ Initially, the P. edulis f. flavicarpa seed oil $(0.1 \mathrm{~g})$ was placed in a tube with $1 \mathrm{~mL}$ of ethanolic $\mathrm{KOH}$ solution $\left(1 \mathrm{~mol} \mathrm{~L} \mathrm{~L}^{-1}\right)$. The solution was incubated into the water bath (Fisatom, Brazil) at $70{ }^{\circ} \mathrm{C}$ for $50 \mathrm{~min}$. After cooling, $1 \mathrm{~mL}$ of distilled water was added and the unsaponifiable fraction was extracted using liquid-liquid partitioning into distilled water and $5 \mathrm{~mL}$ of $n$-heptane. The organic phase was transferred to a tube containing $\mathrm{Na}_{2} \mathrm{SO}_{4}$, and the extraction was repeated twice with 5 and $4 \mathrm{~mL}$ of $n$-heptane, respectively. All these three extracts were combined and homogenized before injection into the GC system.

\section{Ultrasound-assisted saponification (UAS)}

Saponification was carried out in an ethanolic $\mathrm{KOH}$ solution assisted by ultrasound radiation. Firstly, the concentration of the ethanolic $\mathrm{KOH}$ solution $(0.5,1$ and $2 \mathrm{~mol} \mathrm{~L}^{-1}$ ) and the incubation time (15 and $30 \mathrm{~min}$ ) were evaluated. For this, the P. edulis f. flavicarpa seed oil $(0.1 \mathrm{~g})$ was placed in a tube with $1 \mathrm{~mL}$ of ethanolic $\mathrm{KOH}$ solution. Then, the mixture was immersed into an ultrasonic bath at $70^{\circ} \mathrm{C}$. After cooling, $1 \mathrm{~mL}$ of distilled water was added and the unsaponifiable fraction was extracted with $5 \mathrm{~mL}$ of $n$-heptane. The organic phase was transferred to a test tube containing $\mathrm{Na}_{2} \mathrm{SO}_{4}$ and the extraction was repeated twice with 5 and $4 \mathrm{~mL}$ of $n$-heptane, respectively. The organic phases were combined and homogenized before injection into the GC system. Under the optimum conditions, passion fruit seed oil was saponified at different temperatures (30 and $50{ }^{\circ} \mathrm{C}$ ) and the unsaponifiable fraction was extracted with $n$-heptane under the same conditions described above.

\section{Chromatographic analysis}

Gas chromatographic analysis was performed using an Ultra Trace Triplus (Thermo Scientific, Italy) gas chromatography (GC) equipped with a programmed temperature vaporizing (PTV) injector and a TriPlus auto sampler and a flame ionization detection (FID). Chromatographic separation was performed using a capillary column $(30 \mathrm{~m} \times 0.25 \mathrm{~mm}$ i.d. $\times 0.25 \mu \mathrm{m}$ of $5 \%$ diphenyl and $95 \%$ dimethylpolysiloxane) from Macherey-Nagel. The samples $(1 \mu \mathrm{L})$ were on-column injected at $110{ }^{\circ} \mathrm{C}$ and increased to $320{ }^{\circ} \mathrm{C}$ at $14.5^{\circ} \mathrm{C} \mathrm{s}^{-1}$. The GC-FID oven program was as follows: start at $220^{\circ} \mathrm{C}$, hold for $2 \mathrm{~min}$ and then heat to $320{ }^{\circ} \mathrm{C}$ at $20{ }^{\circ} \mathrm{C} \mathrm{min}-1$, final hold time of $11 \mathrm{~min}$. The gas flow rates used were

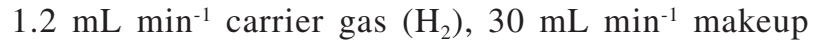

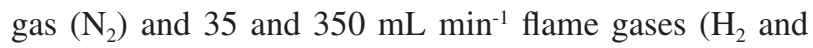
synthetic air, respectively). The retention times and areas of the peaks of the target compounds were determined by ChromQuest $^{\mathrm{TM}} 5.0$ software. ${ }^{37}$ The identification of the phytosterols was performed by comparing the retention times of the samples to those of the standards.

Since blank samples were not available, the quantitative analysis was performed by means of the standard addition method, analyzing passion fruit seed oils at five concentration levels between 0.25 and $30 \mu \mathrm{g} \mathrm{g}^{-1}$. This made it possible to estimate the unknown amount of the analytes (endogenous amount) and to evaluate the linear dynamic range. The results were expressed as milligrams per gram of oil $\left(\mathrm{mg} \mathrm{g}^{-1}\right)$.

\section{Analytical performance}

The Eurachem guideline ${ }^{36}$ was used for the evaluation of linearity, accuracy, precision, the limit of detection (LOD) and the limit of quantitation (LOQ). The accuracy was estimated in terms of recovery and precision (intraday and interday), expressed in terms of relative standard deviations (RSDs), by spiked passion fruit seed oil samples at two concentration levels ( 0.50 and $1.00 \times$ endogenous amount), analyzing five replicates at each concentration. The interday precision was evaluated on two consecutive days. The LOD and LOQ were estimated based on signal to noise ratios of 3 and 10, respectively, after having determined the endogenous amount of the target compounds in the passion fruit seed oils.

\section{Statistical analysis}

Data were presented as mean and standard deviation (SD) values. Statistica ${ }^{\circledR}$ V. 8.0 software $^{37}$ was used for the analysis of Tukey's test $(p<0.05)$. 


\section{Results and Discussion}

\section{Ultrasound-assisted saponification (UAS)}

The determination of phytosterols in passion fruit seed oil was performed by a lipid extraction, followed by a saponification step and GC-FID analysis. Initially, three lipid extraction methods were evaluated (Bligh and Dyer, hexane/ethanol/water and UAE), focusing on the yield of the oil extracted from passion fruit seeds. As can be observed in Figure 1A, a higher extraction yield $(35.5 \pm 1.7 \%)$ was obtained by UAE, followed by the Bligh and Dyer $(23.4 \pm 3.1 \%)$ and hexane/ethanol/water methods $(20.4 \pm 1.9 \%)$. Then, to evaluate whether the extraction yield influences the extracted amount of the target phytosterols, the oil obtained by each extraction method was subjected to a saponification step according to Costa et al.,${ }^{35}$ and the results are presented in Figure 1B.

It can be noted that the influence of the yield of the oil extraction methods on the amount of the compounds extracted from the passion fruit seed oils was more evident for campesterol, which was determined in a higher amount when the oil was extracted by UAE. Alternatively, for stigmasterol and $\beta$-sitosterol, the amounts extracted by UAE and the Bligh and Dyer method did not present significant differences. Based on these results, and considering the easier use, time saving and practicality, UAE was chosen as the oil extraction method from the passion seeds for the subsequent development of the proposed saponification method.

Several conventional saponification methods applied for phytosterol analysis in plant matrices are described in the literature..$^{25-38}$ These conventional methods are based on the use of an ethanolic $\mathrm{KOH}$ solution under

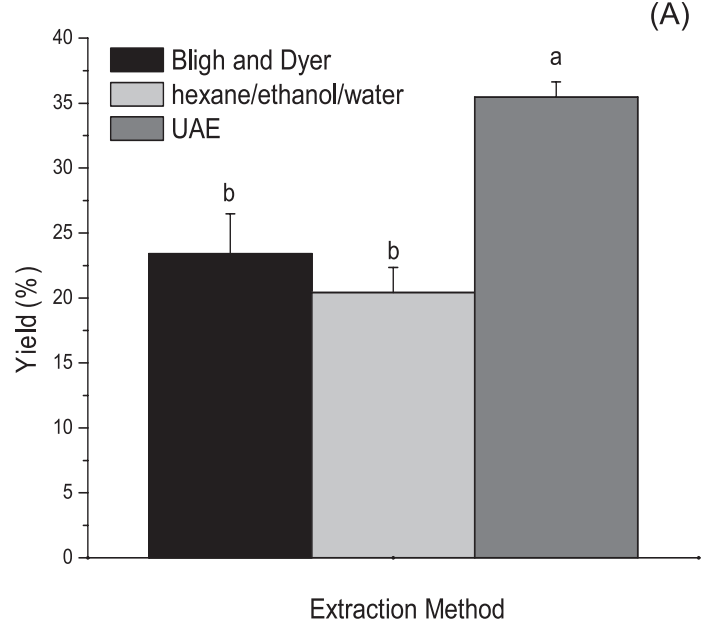

controlled conditions of time and temperature. The $\mathrm{KOH}$ concentrations ranged from 0.5 to $2 \mathrm{~mol} \mathrm{~L}^{-1}$, while the incubation times ranged from $50 \mathrm{~min}$ to $18 \mathrm{~h}$ and the temperatures ranged from room temperature to $80{ }^{\circ} \mathrm{C} .{ }^{22,24,25,38}$

However, a critical aspect for phytosterol analysis is their thermolabile properties, which can lead to degradation of these compounds at high temperatures when long incubation times are used. ${ }^{38}$

Thus, to evaluate the efficiency of the UAS for the extraction of the three target compounds (campesterol, $\beta$-sitosterol and stigmasterol, from passion fruit seed oils), three parameters were investigated, namely, ethanolic $\mathrm{KOH}$ concentration $\left(0.5,1\right.$ and $\left.2 \mathrm{~mol} \mathrm{~L}^{-1}\right)$, incubation time (15 and $30 \mathrm{~min})$ and temperature $\left(30,50\right.$ and $\left.70^{\circ} \mathrm{C}\right)$.

In Figure 2, the performance of the conventional and UAS saponification methods are summarized. As can be observed, all target compounds were determined using both saponification methods, conventional and UAS. However, although the extracted concentrations of all phytosterols did not present significant difference between the conventional saponification method and the UAS method at $70{ }^{\circ} \mathrm{C}$ in all $\mathrm{KOH}$ concentrations evaluated, the last ones presented slightly better numerical results. From the results obtained by the different parameters evaluated during the UAS method optimization, some observations can be made. The extraction time and concentration of ethanolic $\mathrm{KOH}$ solution did not affect the extraction efficiency for all compounds. On the other hand, for a fixed ethanolic $\mathrm{KOH}$ solution concentration and extraction time, it can be observed that the temperature was the parameter that significantly affected the extraction concentrations of all compounds: the lower the temperature, the lower the extracted concentration. Xiao-Hua et al. ${ }^{25}$ and Feng et al. ${ }^{39}$

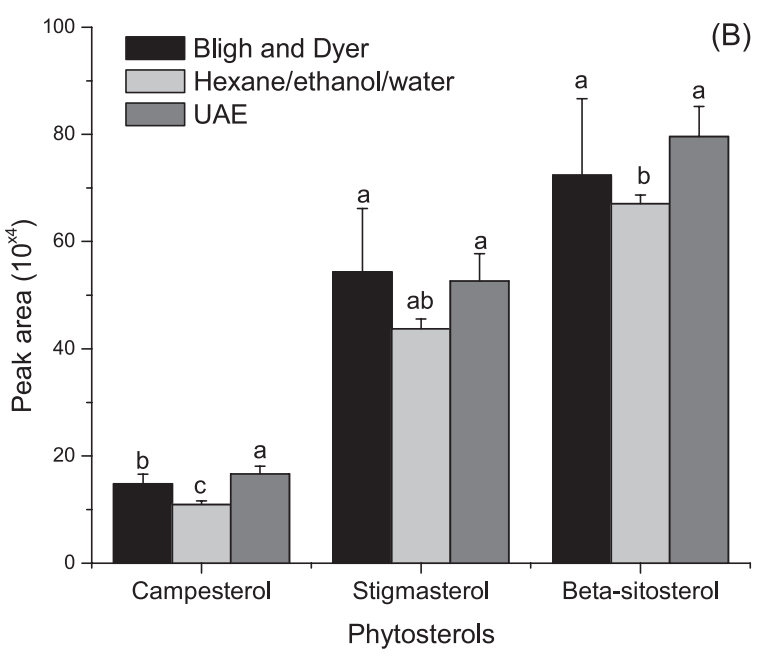

Figure 1. Effects of lipid extraction methods (Bligh and Dyer, hexane/ethanol/water and ultrasound-assisted extraction (UAE)) on the oil yield (A) and extracted amounts of the phytosterols (B) from yellow passion fruit seeds. Different letters indicate significant differences by the Tukey's test at the $5 \%$ level. 


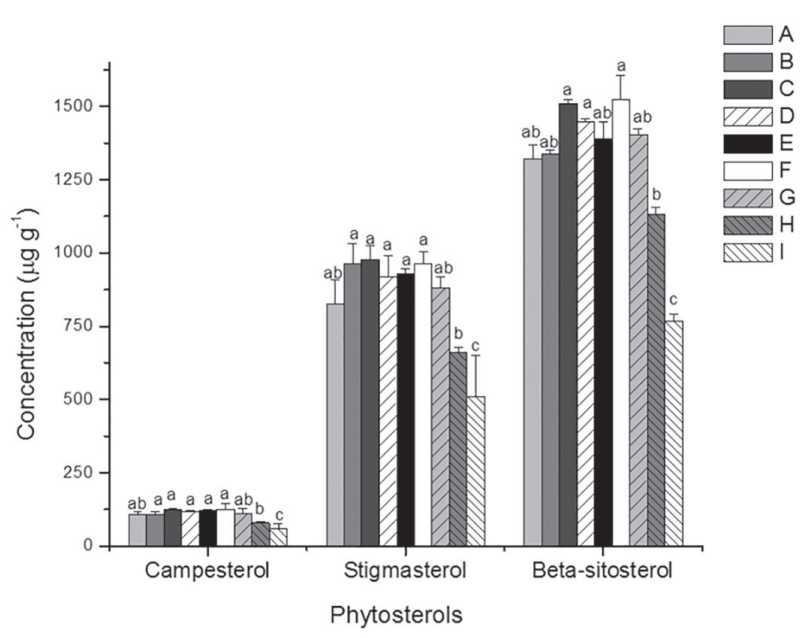

Figure 2. Effects of conventional and ultrasound-assisted saponification (UAS) methods on the extracted concentrations of the phytosterols. Different letters indicate significant differences by the Tukey's test at 5\% level. (A) Conventional saponitication; (B) UAS $15 \mathrm{~min}$ at $70^{\circ} \mathrm{C}$ and $\mathrm{KOH}\left(0.5 \mathrm{~mol} \mathrm{~L}^{-1}\right)$; (C) UAS $15 \mathrm{~min}$ at $70{ }^{\circ} \mathrm{C}$ and $\mathrm{KOH}\left(1 \mathrm{~mol} \mathrm{~L}^{-1}\right)$; (D) UAS $15 \mathrm{~min}$ at $70^{\circ} \mathrm{C}$ and $\mathrm{KOH}\left(2 \mathrm{~mol} \mathrm{~L}^{-1}\right)$; (E) UAS $30 \mathrm{~min}$ at $70^{\circ} \mathrm{C}$ and $\mathrm{KOH}\left(0.5 \mathrm{~mol} \mathrm{~L}^{-1}\right)$; (F) UAS $30 \mathrm{~min}$ at $70{ }^{\circ} \mathrm{C}$ and $\mathrm{KOH}\left(1 \mathrm{~mol} \mathrm{~L}^{-1}\right)$; (G) UAS $30 \mathrm{~min}$ at $70^{\circ} \mathrm{C}$ and $\mathrm{KOH}\left(2 \mathrm{~mol} \mathrm{~L}^{-1}\right)$; (H) UAS $15 \mathrm{~min}$ at $30^{\circ} \mathrm{C}$ and $\mathrm{KOH}\left(1 \mathrm{~mol} \mathrm{~L}^{-1}\right)$; (I) UAS $15 \mathrm{~min}$ at $50{ }^{\circ} \mathrm{C}$ and $\mathrm{KOH}\left(1 \mathrm{~mol} \mathrm{~L}^{-1}\right)$.

also reported that a higher extraction temperature is beneficial for saponification of phytosterol contents. Furthermore, as stated in the literature, temperature is strongly associated with solvents properties, and an increase of temperature results in a decrease of both viscosity and surface tension, and induces an improvement in the mass transfer mechanism. ${ }^{30,40}$ Thus, the selected conditions for the UAS were an ethanolic $\mathrm{KOH}$ solution concentration of $1 \mathrm{~mol} \mathrm{~L}^{-1}$ and an extraction time and temperature of $15 \mathrm{~min}$ and $70{ }^{\circ} \mathrm{C}$, respectively.

By comparing the results of the extracted concentrations of the target compounds obtained with the optimized UAS method and with the conventional saponification method, it is possible to conclude that in addition to the increase in the extraction efficiency, the saponification time decreased about 3.3 times. The extraction time decrease can be associated to the cavitation effects promoted by the use of ultrasonic radiation during the saponification step. ${ }^{41}$

\section{Analytical performance}

The analytical performance of the developed method was evaluated in terms of selectivity, linearity, LOD, LOQ, accuracy and precision for campesterol, $\beta$-sitosterol and stigmasterol.

The selectivity of the method was evaluated by comparing the retention times of the target and matrix compounds and the analytical curves obtained by standard addition method and external standard method. Considering that the curves were parallel, ${ }^{42}$ it was possible to conclude that there were no matrix compounds that could affect the quantification of phytosterols (Figure 3).

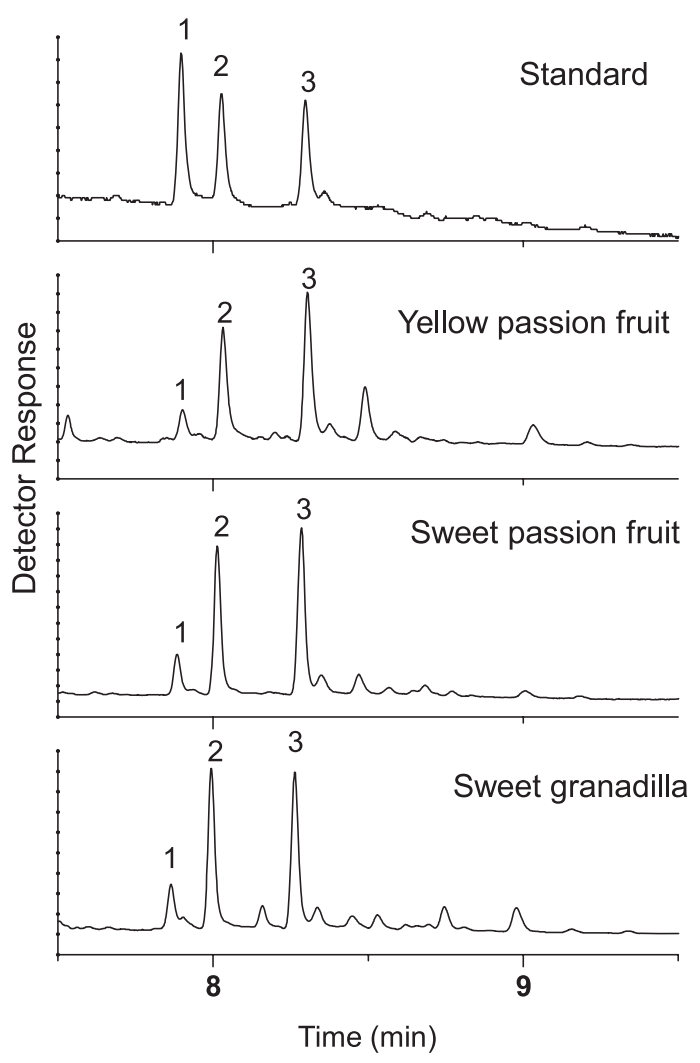

Figure 3. Chromatograms of standards and passion fruit seed oils. Peak identification: (1) campesterol, (2) stigmasterol and (3) $\beta$-sitosterol.

A standard addition method at five concentrations $(0.25,0.5,1.0,2.0$ and $3 \times$ endogenous amount $)$ was used to determine the method's linearity. As shown in Table 1, the developed method presented good linearity for all the selected compounds with correlation coefficients higher than 0.99 .

The LOD and LOQ were calculated as the quantity of analyte able to produce a chromatographic peak three and ten times higher, respectively, than the noise of the baseline in a chromatogram of a non-fortified sample, after having estimated the endogenous amount. These values are shown in Table 1 and were satisfactory to quantify the target compounds at the concentration levels determined in the samples.

The accuracy was estimated through recovery studies at two concentration levels ( 0.5 and 1 times the endogenous amount of each compound). For this, after preliminary determination of the endogenous amount of the phytosterols, some samples were spiked with known amounts of the analytes and, after $30 \mathrm{~min}$ of equilibration time, submitted to the saponification process (spiked sample). 
Table 1. Analytical performance of the developed method

\begin{tabular}{|c|c|c|c|c|c|c|c|c|c|}
\hline & \multirow{2}{*}{$\begin{array}{l}\text { Linear range / } \\
\qquad\left(\mu \mathrm{g} \mathrm{g}^{-1}\right)\end{array}$} & \multicolumn{2}{|c|}{ Linear regression } & \multirow{2}{*}{$\begin{array}{l}\mathrm{LOD}^{\mathrm{b}} / \\
\left(\mu \mathrm{kg}^{-1}\right)\end{array}$} & \multirow{2}{*}{$\begin{array}{l}\mathrm{LOQ}^{\mathrm{c}} / \\
\left(\mu \mathrm{g} \mathrm{kg}^{-1}\right)\end{array}$} & \multicolumn{2}{|c|}{ Recovery $^{\mathrm{d}} / \%$} & \multicolumn{2}{|c|}{$\begin{array}{c}\text { Inter-day precision } \\
(\mathrm{RSD} / \%)\end{array}$} \\
\hline & & $y=a+b x$ & $\mathrm{r}^{\mathrm{a}}$ & & & F1 & $\mathrm{F} 2$ & $\mathrm{~F} 1$ & $\mathrm{~F} 2$ \\
\hline Campesterol & $0.25-3.0$ & $y=1.110000+1563.78 x$ & 0.993 & 21 & 70 & $104(10)^{\mathrm{d}, \mathrm{e}}$ & $107(11)$ & 7 & 19 \\
\hline Stigmasterol & $1.0-15.0$ & $\mathrm{y}=4.980000+850.201 \mathrm{x}$ & 0.995 & 42 & 140 & $107(8)$ & $103(11)$ & 6 & 11 \\
\hline$\beta$-sitosterol & $2.0-30.0$ & $y=6.230000+827.2050 x$ & 0.996 & 54 & 180 & $107(8)$ & $106(10)$ & 5 & 10 \\
\hline
\end{tabular}

F1: spiked level of 0.50 times endogenous amount; F2: spiked level of 1 times endogenous amount. ${ }^{\mathrm{a} C o r r e l a t i o n}$ coefficient; bimit of detection; ${ }^{\mathrm{c}}$ limit of quantification; ' recovery and precision values (intra and inter-day) values obtained analyzing five replicates at each concentration $(n=5)$; intra-day values expressed as relative standard deviation (RSD) are given in parentheses.

Other samples were directly submitted to the saponification process and the fortification was applied on the final extract with the same nominal amount of analyte (control sample). Satisfactory recoveries (Table 1), ranging between 103 and 107\%, were obtained for all compounds at both concentration levels evaluated.

Finally, the precision was calculated in terms of intraday and interday precision and expressed in terms of RSD. The results are presented in Table 1 with all RSD values at $\leq 19 \%$ for all compounds studied.

\section{Analysis of passion fruit seed oils from different species}

The method developed was applied for the determination of campesterol, $\beta$-sitosterol and stigmasterol in the seed oils of three different species of passion fruits, namely, yellow passion, sweet passion and sweet granadilla. As can be observed in Table 2, all target phytosterols were found in the seed oils of all passion fruit species evaluated. $\beta$-Sitosterol was the compound found at the highest concentration levels, varying in the range of $0.90 \pm 0.02$ to $1.60 \pm 0.01 \mathrm{mg} \mathrm{g}^{-1}$ of oil, followed by stigmasterol $\left(0.70 \pm 0.01\right.$ to $1.40 \pm 0.12 \mathrm{mg} \mathrm{g}^{-1}$ of oil) and campesterol $\left(0.10 \pm 0.01\right.$ to $0.30 \pm 0.06 \mathrm{mg} \mathrm{g}^{-1}$ of oil). Among the passion fruit seeds oil species evaluated, sweet passion fruit seed oil presented the highest phytosterol content, followed by yellow passion fruit and sweet granadilla.

Table 2. Results for the determination of campesterol, $\beta$-sitosterol and stigmasterol in seeds oil of three different species of passion fruits: yellow passion, sweet passion and sweet granadilla

\begin{tabular}{lccc}
\hline Phytosterol & $\begin{array}{c}\text { Yellow passion } \\
\text { fruit / }\left(\mathrm{mg} \mathrm{g}^{-1}\right)\end{array}$ & $\begin{array}{c}\text { Sweet passion } \\
\text { fruit / }\left(\mathrm{mg} \mathrm{g}^{-1}\right)\end{array}$ & $\begin{array}{c}\text { Sweet granadilla / } \\
\left(\mathrm{mg} \mathrm{g}^{-1}\right)\end{array}$ \\
\hline Campesterol & $0.10^{\mathrm{c}} \pm 0.01$ & $0.30^{\mathrm{a}} \pm 0.06$ & $0.20^{\mathrm{b}} \pm 0.02$ \\
Stigmasterol & $0.80^{\mathrm{b}} \pm 0.01$ & $1.40^{\mathrm{a}} \pm 0.12$ & $0.70^{\mathrm{c}} \pm 0.01$ \\
$\beta$-Sitosterol & $1.00^{\mathrm{b}} \pm 0.04$ & $1.60^{\mathrm{a}} \pm 0.01$ & $0.90^{\mathrm{c}} \pm 0.02$ \\
\hline
\end{tabular}

Values are the mean \pm standard deviation $(n=3)$. Different letters in the same line represent statistical different according to Tukey's test $(p<0.05)$.
Several works that describe the analysis of the same representative phytosterols analyzed in the present seed oils, such as soybean, sunflower, corn, Zhejiang pecan and Sacha inchi, can be found in the literature..$^{22,41,43}$ By comparing these works with the present work, it can be noted that a similar behavior related to the relative quantities of each compound was found in the seeds oils, with $\beta$-sitosterol as the compound found in the highest abundance. Alternatively, comparing the concentrations found in passion fruit seed oil with the other seed oils, the concentrations found in passion seed oil were about twice as high than Zhejiang pecan oil and Sacha inchi oil and, about 1.5, 2 and 5 times lower than soybean, sunflower and corn oils, respectively. Furthermore, in a recent work published by Siger et al. ${ }^{24}$ a GC-FID method was developed to quantify seven phytosterols (campesterol, $\Delta 5$-stigmasterol, $\beta$-sitosterol, $\Delta 5$-avenasterol, cycloartenol, 24-methylenecycloartanol and citrostadienol) in oil obtained from seeds of beech (Fagus sylvatica L.). Among the compounds analyzed, campesterol, $\beta$-sitosterol and stigmasterol were the compounds found in the higher concentration levels, in agreement with the literature, and, as all other seed oils cited above, $\beta$-sitosterol was the compound found in the highest abundance.

\section{Conclusions}

A simple, time-saving and efficient method for the determination of three representative phytosterols in passion fruit seed oils based on UAS and GC-FID analysis was developed and validated. The proposed method showed good linearity, excellent accuracy, satisfactory precision and low limits of quantification. In addition, the UAS method was optimized for ethanolic $\mathrm{KOH}$ solution concentration, extraction time and temperature. The optimized UAS method extracted higher phytosterol concentrations and was about 3.3 times faster than the conventional saponification method. Thus, the proposed 
UAS method might be a valuable alternative saponification method for the determination of phytosterols in oil samples. Furthermore, the developed method was applied for the analysis of campesterol, $\beta$-sitosterol and stigmasterol from the seed oils of three different species of passion fruits, yellow passion, sweet passion and sweet granadilla. All compounds were found for all passion fruit species evaluated, with $\beta$-sitosterol the most abundant compound, followed by stigmasterol and campesterol.

\section{Acknowledgments}

We would like to thank Conselho Nacional de Desenvolvimento Científico e Tecnológico (CNPq, Brazil), Coordenação de Aperfeiçoamento de Pessoal de Nível Superior (CAPES, Brazil) and Fundação Araucária for support and the scholarship.

\section{References}

1. Marques, S. S. F.; Libonati, R. M. F.; Sabaa-Srur, A. U. O.; Luo, R.; Shejwalkar, P.; Hara, K.; Dobb, T.; Smith, R. E; Rev. Bras. Farmacogn. 2016, 26, 420.

2. Sakalem, M. E.; Negri, G.; Tabach, R.; Rev. Bras. Farmacogn. 2012, 22, 1219.

3. Silva, J. K.; Cazarin, C. B. B.; Colomeu, T. C.; Batista, A. G.; Meletti, L. M. M.; Paschoal, J. A. R.; Bogusz Júnior, S.; Furlan, M. F.; Reyes, F. G. R; Augusto, F.; Maróstica Júnior, M. R.; Zollner, R. L.; Food. Res. Int. 2013, 53, 882.

4. Corrêa, R. C. G.; Peralta, R. M.; Haminiuk, C. W. I.; Maciel, G. M.; Bracht, A.; Ferreira, I. C. F. R; Trends Food Sci. Technol. 2016, 58, 79.

5. López-Vargas, J. H.; Fernández, J.; Pérez-Álvarez, J.; ViudaMartos, M.; Food Res. Int. 2013, 51, 756.

6. Saravanan, S.; Parimelazhagan, T.; Food Sci. Hum. Wellness 2014, 3, 56.

7. Porto-Figueira, P.; Freitas, A.; Cruz, C. J.; Figueira, J.; Câmara, J. S.; Food Res. Int. 2015, 77, 408.

8. Oliveira, D. A.; Angonese, M.; Gomes, C.; Ferreira, S. R. S.; J. Supercrit. Fluids 2016, 111, 55.

9. Coelho, E. M.; Gomes, R. G.; Machado, B. A. S.; Oliveira, R. S.; Lima, M. S.; Azêvedo, L. C.; Guez, M. A. U.; Food Hydrocolloids 2016, 62, 158.

10. Macagnan, F. T.; dos Santos, L. R.; Roberto, B. S.; de Moura, F. A.; Bizzani, M.; da Silva, L. P.; Bioact. Carbohydr. Diet. Fibre 2015, 6,1 .

11. Pinell, L. O.; Rodrigues, J. S. Q.; Costa, A. M.; de Lima, H. C.; Chiarello, M. D.; Melo, L.; J. Sci. Food Agric. 2015, 95, 1500.

12. Seixas, F. L.; Fukuda, D. L.; Turbiani, F. R. B.; Garcia, P. S.; Petkowicz, C. L. O.; Jagadevam, S.; Gimenes, M. L.; Food Hydrocolloids 2014, 38, 186.
13. Morais, D. R.; Rotta, E. M.; Sargi, S. C.; Schimidt, E. M.; Bonafe, E. G.; Eberlin, M. N.; Sawaya, A. C. H. F.; Visentainer, J. V.; Food Res. Int. 2015, 77, 392.

14. Morais, D. R.; Rotta, E. M.; Sargi, S. C.; Bonafe, E. G.; Suzuki, R. M.; Souza, N. E.; Matsushita, M.; Visentainer, J. V.; J. Braz. Chem. Soc. 2017, 28, 308.

15. Barrales, F. M.; Rezende, C. A.; Martinez, J.; J. Supercrit. Fluids 2015, 104, 183.

16. Viganó, J.; Aguiar, A. C.; Moraes, D. R.; Lara, J. L. P.; Eberlin, M. N.; Cazarin, C. B. B.; Maróstica-Junior, M. R.; Martínez, J.; Food Res. Int. 2016, 85, 51.

17. Malacrida, C. R.; Jorge, N.; Braz. Arch. Biol. Technol. 2012, 55, 127.

18. Perzuatti, P. B.; Sganzerla, M.; Jacques, A. C.; Barcia, M. T.; Zambiazi, R. C.; LWT - Food Sci. Technol. 2015, 64, 259.

19. Silva, A. C.; Jorge, N.; Eur. J. Lipid Sci. Technol. 2016, 119, 1600024.

20. Moreau, R. A.; Whitaker, B. D.; Hicks, K. B.; Prog. Lipid Res. 2002, 41, 457.

21. Srigley, C. T.; Haile, E. A.; J. Food Compos. Anal. 2015, 40, 163.

22. Yang, J.; Zhou, F.; Xiong, L.; Mao, S.; Hu, Y.; Lu, B.; LWT Food Sci. Technol. 2015, 62, 541.

23. Shahzad, N.; Khan, W.; Shadab, M. D.; Ali, A.; Saluja, S. S.; Sharma, S.; Al-Allaf, F. A.; Abduljaleel, Z.; Ibrahim, I. A. A.; Abdel-Wahab, A. F.; Afify, A.; Al-Ghamdi, S. S.; Biomed. Pharmacother. 2017, 88, 786.

24. Siger, A.; Dwiecki, K.; Borzyszkowski, W.; Turski, M.; Rudznska, M.; Nogala-Kalucka, M.; Food Chem. 2017, 225, 239.

25. Xiao-Hua, X.; Yuan, Z.; Li, G.; Sep. Purif. Technol. 2013, 104, 284.

26. Folch, J.; Lees, M.; Stanley, G. H. S.; J. Biol. Chem. 1957, 226, 497.

27. Bligh, E. G.; Dyer, W. J.; Can. J. Biochem. Phys. 1959, 37, 911.

28. AOAC (Association of Official Analytical Chemists); Official Methods of Analysis, 16 th $^{\text {th }}$ ed AOAC International: Gaithersburg, MD, 1995.

29. James, C. S.; Analytical Chemistry of Food; Blackie Academic and Professional: London, UK, 1995.

30. Barizão, E. O.; Boeing, J. S.; Martins, A. C.; Visentainer, J. V.; Almeida, V. C.; Food Anal. Methods 2015, 8, 2392.

31. Biondo, P. B. F.; dos Santos V. J.; Montanher, P. F.; OliveiraJunior, O. O. S.; Matsushita, M.; Almeida, V. C.; Visentainer, J. V.; Anal. Methods 2015, 7, 9773.

32. Duchateau, G. S. M. J. E.; Bauer-Plank, C. G.; Louter, A. J. H.; van der Ham, M.; Boerma, J. A.; van Rooijen, J. J. M.; Zandbelt, P. A.; J. Am. Oil Chem. Soc. 2002, 79, 273.

33. Khoddami, A.; Wilkes, M. A.; Roberts, T. H.; Molecules 2013, $18,2328$.

34. Vardanega, R.; Santos, D. T.; Meireles, M. A. A.; Pharmacogn. Rev. 2014, 8, 88. 
35. Costa, P. A.; Ballus, C. A.; Teixeira-Filho, J.; Godoy, H. T.; Food Res. Int. 2010, 43, 1603.

36. Magnusson, B.; Örnemark, U.; Eurachem Guide: The Fitness for Purpose of Analytical Methods - A Laboratory Guide to Method Validation and Related Topics, $2^{\text {nd }}$ ed.; Eurachem: Teddington, 2014.

37. StatSoft; Statistica 8.0 Software; StatSoft: Tucksa; StatSoft South America: São Paulo, 2007.

38. Duong, S.; Strobel, N.; Buddhadasa, S.; Stockham, K.; Auldist, M.; Wales, B.; Orbell, J.; Cran, M.; Food Chem. 2016, 211, 570.

39. Feng, S.; Liu, S.; Luo, Z.; Tang, K.; Food Chem. 2015, 181, 9.
40. Chemat, F.; Rombaut, N.; Sicaire, A. G.; Meullemiestre, A.; Fabiano-Tixier, A. S.; Abert-Vian, M.; Ultrason. Sonochem. 2017, 34, 540.

41. Winkler, J. K.; Warner, E. K.; Glynn, M. T.; J. Am. Oil Chem. Soc. 2007, 84, 1023.

42. Ribani, M.; Bottili, C. B. G.; Collins, C. H.; Jardim, I. C. S. F.; Melo, L. F. C.; Quim. Nova 2004, 27, 771.

43. Chirinos, R.; Zuloeta, G.; Pedreschi, R.; Mignolet, E.; Larondelle, Y.; Campos, D.; Food Chem. 2013, 141, 1732.

Submitted: July 28, 2017

Published online: September 25, 2017 